\title{
Report-back for geo-referenced environmental data: A case study on personal monitoring of temperature in outdoor workers
}

\author{
Laura Thompson, ${ }^{1}$ Maggie Sugg, ${ }^{1}$ Jennifer Runkle ${ }^{2}$ \\ ${ }^{1}$ Department of Geography and Planning, Appalachian State University, Boone, North Carolina; ${ }^{2}$ North \\ Carolina Institute for Climate Studies, North Carolina State University, Asheville, North Carolina, USA
}

\begin{abstract}
Few studies have evaluated the benefits of reporting back participatory environmental monitoring results, particularly regarding participant motivation toward behavioural modification concerning workplace heat exposure. This study evaluated the individual data report-back for geo-located environmental temperature and time activity patterns in grounds maintenance crews in three geographic regions across the South-eastern United States. Surveys collected information on worker interpretation of their results and intended action(s) to reduce heat exposure. Worker
\end{abstract}

Correspondence: Laura Thompson, Department of Geography and Planning, Appalachian State University, P.O. Box 32066, Boone, North Carolina 28608, USA.

Tel.: 865.386.6622.

E-mail: thompsonlk1@appstate.edu

Key words: Citizen science; Environmental health literacy; Participatory environmental monitoring; Occupational heat exposure; Data report-back.

Acknowledgments: we thank the grounds maintenance managers and crew members from each university for their enthusiastic participation in this research. We also thank Dr. Christopher Fuhrman for providing report-back data for our MSU worksite.

See online Appendix for additional Figures.

Contributions: the authors contributed equally.

Conflict of interest: the authors declare no potential conflict of interest.

Funding: this research was supported in part by a Grant from the Appalachian State University's University Research Council and the Oak Ridge Associated Universities Travel Grant.

Received for publication: 5 October 2017.

Revision received: 13 November 2017.

Accepted for publication: 19 November 2017.

CCopyright L. Thompson et al., 2018

Licensee PAGEPress, Italy

Geospatial Health 2018; 13:629

doi:10.4081/gh.2018.629

This article is distributed under the terms of the Creative Commons Attribution Noncommercial License (CC BY-NC 4.0) which permits any noncommercial use, distribution, and reproduction in any medium, provided the original author(s) and source are credited. response was highly positive, especially among more experienced workers who expressed a greater willingness to modify personal behaviour to reduce heat stress. Individual-level report-back of environmental data is a powerful tool for individuals to understand and act on their personal exposure to heat.

\section{Introduction}

Citizen science is the process by which members of the general public partner with professional scientists to collect, analyze, and interpret data on local or regional issues of concern (Bonney et al., 2016). The field of citizen science has expanded rapidly in the last several years with the development of GPS-enabled smart phones that allow participants to readily provide information and geolocations about situations in real-time. Coupled with smart sensors, low-cost smartphone sensing technology has significant potential to broaden the geographic and time scales of environmental exposure measurement. These instruments can empower underrepresented communities not traditionally involved in research to not only engage in the scientific and decision-making process, but also provide high-resolution environmental monitoring data to creatively address place-based individual and community health concerns (Reis et al., 2015).

At an aggregate level, citizen scientists can serve as human sensors (Goodchild, 2007) via volunteer environmental monitoring and provide real or near real-time surveillance on populationlevel health trends playing the role of early warning systems (Newman et al., 2012) or assist in the design of targeted public health interventions. Although the use of these emerging technologies combined with citizen scientists will likely provide quality improvements in data collection by capturing geo-referenced, real-time personal measurements, an equally important challenge is how to communicate exposure data back to participants in a manner that increases scientific understanding, spurs action-based behavioural change and promotes environmental health literacy (Ramirez-Andreotta et al., 2016). To the authors' knowledge, no previous studies have examined temperature-health vulnerability in at-risk worker populations by linking georeferenced data on temperature exposure and time activity patterns, nor have these studies promoted environmental health literacy among research participants by communicating individual and group-level findings using various mapping and visualization formats.

Citizen science is an evolving discipline (Newman et al., 2012) that has experienced a publication surge in the last decade, particularly within the disciplines of biology and ecology, GIS sciences, the social sciences and epidemiology (Kullenberg, 2016). Citizen science can be classified according to participants' engagement level, ranging from citizens being used as sensors all 
the way to co-deciding with researchers the types of data to be collected and the ways in which findings may be translated into effective policy-making (Den Broader et al., 2016). While citizen science has been linked to community (e.g., increased social capital, enhanced trust among stakeholders, elevated awareness of a placebased issue and effective policy-making) as well as to individual outcomes (e.g., gains in knowledge, behavioural change and more effective civic participation), there are a number of knowledge gaps that must be addressed, including: i) evaluating the effectiveness of citizen participation in influencing decision-making; ii) research on changes in attitudes and behaviour; iii) studies on whether or not citizen science empowers communities and individuals to improve their well-being (Stepnuck et al., 2015; Bonney et al., 2016).

Environmental Health Literacy (EHL) is a separate, emerging concept that is evolving by drawing from risk communication, environmental health sciences, health literacy and communication science (Finn and O'Fallon, 2015; National Institute of Environmental Health Sciences (NIEHS), 2016). Recent research examining EHL in community engagement exposure assessment studies demonstrates that participants desire and respond favourably to maps and visualization (i.e., spatial methods) of personal exposure data as a helpful format in reporting back individual and community-level results (Ramirez-Andreotta et al., 2016). More research is needed on EHL-driven methodology to address a key challenge in GIScience concerning the effective reporting back of location-based environmental exposure data for public consumption, with special attention on how to approach multi-dimensional data integration, analysis, visual representation and interpretation of dynamic and complex environmental-health interactions among participants (National Research Council, NRC, 2006; Gould, 2010). Environmental health studies engage and partner with communities grappling with environmental health threats. In many cases, study results can directly benefit these individuals and their communities by informing action- and evidence-based strategies to reduce environmental exposures. A recent trend has emerged in which researchers conducting biomonitoring studies at the individual and household levels assume a right to know stance - participants have a right to know or not know their personal exposure results (a notion usually introduced in the informed consent process) - and are provided with these results via a planned data report-back mechanism (Adams et al., 2011; Dunagan et al., 2013; Brody et al., 2014; Judge et al., 2016; Ramirez-Andreotta et al., 2016). The report-back process involves developing appropriate formats and data visualization methods for presenting and contextualizing results to non-scientific audiences with varying levels of scientific literacy. However, the choice of which risk communication strategy or data visualization method results in the most effective report-back of environmental exposure data for promoting understanding, behavioural change and action is a continual challenge for many researchers (Ramirez-Andreotta et al., 2016).

To help guide researchers on the design and implementation of report-back materials, the Silent Spring Institute (https://silentspring.org/) published a report-back handbook, a how to manual describing different approaches to communication on the types of environmental contaminants found in a participant's biosamples, as well as the concentration detected in a comparative context (e.g., compared to the distribution of others in the study or a comparable nationally representative reference group), followed by recommendations concerning the exposure-reduction steps a participant should consider (Dunagan et al., 2013). Often, there is considerable uncertainty surrounding the implications of a particular environmental exposure on human health, and researchers can acknowledge this uncertainty through honesty and clearly communicating to participants that in some cases there is simply not enough scientific understanding concerning the health effects of certain environmental exposure levels (Dunagan et al., 2013; Brody et al., 2014). Report-back is increasingly becoming standard practice for both academic researchers and governmental institutions, further highlighting the need for additional studies that evaluate and provide evidence on how to refine the report-back process.

Whether assessing learning outcomes at the community and individual levels, EHL provides a framework for understanding how people interpret and respond to environmental health information. This can be used to evaluate learning, behavioural and attitude change outcomes from the report-back process. EHL encompasses an individual's ability to understand, evaluate and use environmental health information to reduce risk and improve personal and environmental health (Society for Public Health Education, 2016). Report-back assessments to date have used qualitative methods in the form of semi-structured interviews that focus on developing an understanding of participant's experience during the study, motivations for participating in the research process, interpretation and emotional response to results and any actions taken or considered in response to results (Adams et al., 2011; Dunagan et al., 2013; Judge et al., 2016; and Ramirez-Andreotta et al., 2016). EHL advances health literacy beyond its traditional assessment of literacy skills such as reading and writing, moving towards an understanding of actions and skills-based literacy that focuses on an individual's ability to reduce risk and improve personal and environmental health through action and decision-making (Society for Public Health Education, 2016). Yet, few studies have evaluated the benefits of volunteer monitoring efforts on individuals and partnering communities, including changes in attitudes or behaviour concerning environmental exposure.

The objective of this study was to evaluate the data reportback for a larger study involving personal monitoring of environmental temperature and geo-referenced time activity patterns in grounds maintenance crews at three universities in South-eastern United States. To the authors' knowledge, this case study is the first report-back assessment extending beyond human biomonitoring studies to examine the evaluation of location-based environmental exposure information in a vulnerable occupational group. This study aimed to provide a new framework for citizen scientists to engage in location-based environmental monitoring and use of high-resolution spatio-temporal data to evaluate their own environmental health conditions. Results from the report-back survey should inform researchers on ways to share results with participants and allow for the refinement and development of new reportback tools and protocols to be used in environmental exposure studies collecting geo-referenced data.

\section{Materials and Methods}

\section{Personal monitoring of occupational heat exposure study}

The study population included grounds maintenance crews from three universities in South-eastern United States: 
Appalachian State University (ASU), North Carolina State University (NCSU) and Mississippi State University (MSU). A regional map and aerial imagery for each campus is provided in Figure 1. Data on temperature exposure, heart rate, health symptoms, and time activity patterns were collected on a total of 66 outdoor workers during the summer of 2016 (July 11 to August 8). Each participant was monitored for a consecutive 5-day work week using GPS data. Figure 2 shows campus maps for each study site overlaid with a point density layer identifying the regions of campus that were more frequently occupied by study participants. ASU is a rural campus located in Boone, North Carolina, a rural city of 18,000 people in the southern Appalachian mountains of western North Carolina. ASU is also one of the highest elevation campuses east of the Mississippi River at over 3,000 feet above sea level (U.S. Census 2015b). MSU is a rural campus located in Starkville, Mississippi, with a population of over 25,000 people
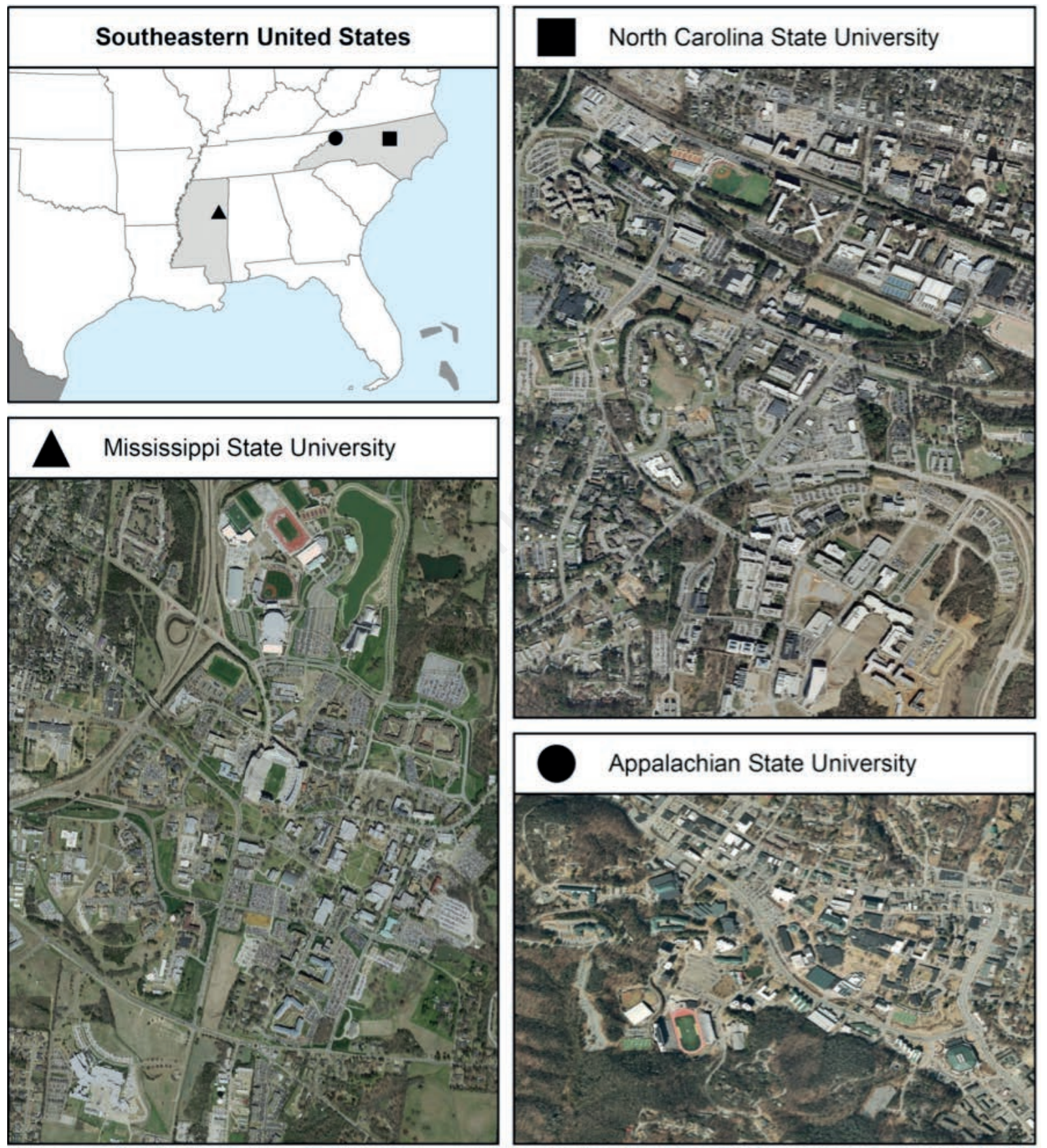

Figure 1. Study area map depicting the region and individual sites for the study. Orthographic Imagery was available through the North Carolina Center for Geographic Data and Analysis 2013 and 2014 Appalachian State University imagery hosted by NC OneMap and the Mississippi Coordinating Council for Remote Sensing and GIS 2014 imagery hosted by the Mississippi Automated Resource Information System. 
(U.S. Census 2015c). NCSU is an urban campus located in Raleigh, North Carolina, a large city of just over 450,000 people (U.S. Census 2015a). Each campus and location is geographically and climatologically diverse with high summer temperatures and humidity at MSU (30-year climate normals, 1981-2010, maximum temp is $91.5\left(33^{\circ} \mathrm{C}\right)$ in July), high summer temperatures at NCSU (30-year climate normals maximum temp is $90.2\left(32.3^{\circ} \mathrm{C}\right)$ in
July), and relatively cooler summer temperatures and lower humidity at ASU (30-year climate normals maximum temp is 78.9 $\left(26.1{ }^{\circ} \mathrm{C}\right)$ in July). Climate normals refer to a 30 -year average of temperature issued by the US National Oceanic and Atmospheric Administration and are considered a measure of central tendency for any locale's climate (Arguez et al., 2012).
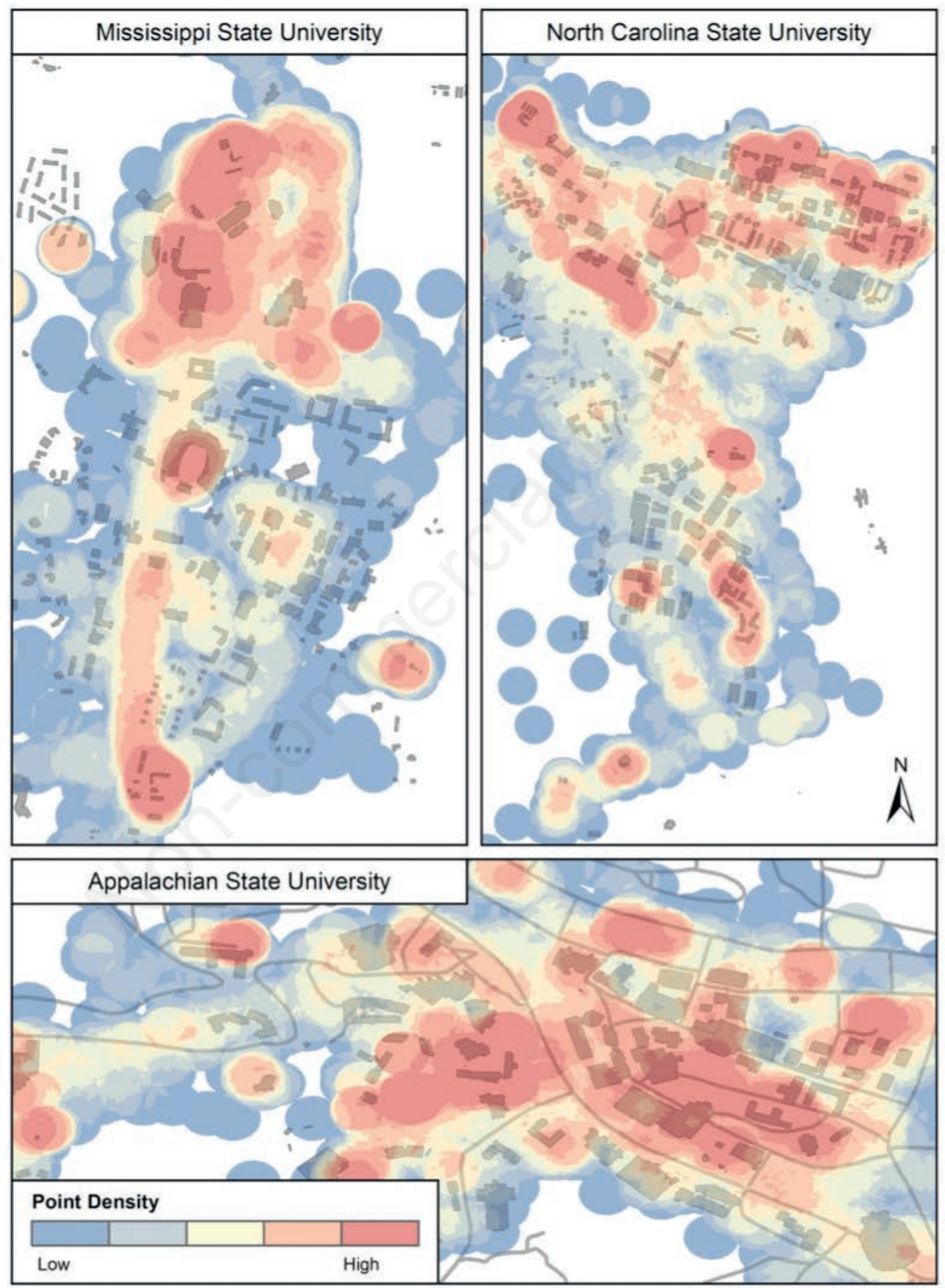

Figure 2. Point density maps for each study site depicting the spatial distribution of GPS coordinates of personal temperature exposure. point density surfaces and maps were created in ArcMap 10.3 and were generated using the GPS points from all study participants. An output cell size of 2 meters ( 1 meter for ASU) and a 90 meters (50 meters for ASU) window were used as point density parameters. The total number of GPS coordinates for temperature exposure for ASU, NCSU, and MSU were approximately 8300, 13000, and 4600, respectively. 


\section{Survey development}

Report-back sessions were held at each university following the summer data collection period and included explanations of study results from researchers and the distribution of an individual exposure results packet containing a variety of visualization formats for interpreting individual and group-level heat exposure to each participant. Report-back visualizations included tables showing maximum, minimum and average temperature at participant and university levels and a box plot comparing the experienced temperatures for each school across the four weeks (Figure 3; Appendix Figures A1 and A2). Figures 4 and 5 show the two line graph visualizations provided, one comparing individual experienced temperature to weather station temperature and one comparing individual recorded heart rate to the recommended resting heart rate range (Appendix Figure A3). Participants were also provided with interpolated temperature maps as a tool for visualizing their personal temperature exposure across campus. Interpolations were derived from participants' monitored ambient temperature and corresponding GPS coordinates (Figure 6 and Appendix Figure A4). This map shows temperature exposure across campus, allowing participants to identify areas of greatest temperature exposure. Report-back visualizations were created in ArcGIS 10.1 and $\mathrm{R}$ statistical software 2.14 .0 with the package ggplot2. In addition to these visualizations, participants received recommendations for mitigating heat exposure while at work (Appendix Figure A5) and given a survey prior to data collection to assess pre-study and post-study behavioural changes.

A survey was distributed at the end of the report-back session after participants examined their individual results and a question and answer period with the research team. The survey was avail-

\section{Summary of Your Results}

Over the course of the workweek in which you participated, your daily temperature exposure profile was:

\begin{tabular}{|l|l|l|l|l|l|}
\hline You & \multicolumn{1}{|c|}{$\begin{array}{c}\text { Monday } \\
7 / 18\end{array}$} & $\begin{array}{c}\text { Tuesday } \\
7 / 19\end{array}$ & $\begin{array}{c}\text { Wednesday } \\
7 / 20\end{array}$ & $\begin{array}{c}\text { Thursday } \\
7 / 21\end{array}$ & $\begin{array}{c}\text { Friday } \\
7 / 22\end{array}$ \\
\hline Average Temperature & $82.2^{\circ}$ & $82.6^{\circ}$ & $85.3^{\circ}$ & $88.1^{\circ}$ & $83.8^{\circ}$ \\
\hline Max Temperature & $91.4^{\circ}$ & $92.3^{\circ}$ & $96.8^{\circ}$ & $101.3^{\circ}$ & $91.4^{\circ}$ \\
\hline Minimum Temperature & $73.4^{\circ}$ & $76.1^{\circ}$ & $77.0^{\circ}$ & $77.0^{\circ}$ & $71.6^{\circ}$ \\
\hline Humidity & N/A & N/A & N/A & N/A & N/A \\
\hline
\end{tabular}

Below is the daily temperature exposure for other workers at your worksite for the same week:

\begin{tabular}{|c|c|c|c|c|c|}
\hline ASU & $\begin{array}{c}\text { Monday } \\
7 / 18 \\
\text { Individual/ } \\
\text { weather } \\
\text { station }\end{array}$ & $\begin{array}{c}\text { Tuesday } \\
7 / 19\end{array}$ & $\begin{array}{c}\text { Wednesday } \\
7 / 20\end{array}$ & $\begin{array}{c}\text { Thursday } \\
7 / 21\end{array}$ & $\begin{array}{c}\text { Friday } \\
7 / 22\end{array}$ \\
\hline Average Temperature & $\begin{array}{l}80.7^{\circ} \\
76.9^{\circ}\end{array}$ & $\begin{array}{l}80.3^{\circ} \\
75.8^{\circ}\end{array}$ & $\begin{array}{l}81.7^{\circ} \% \\
76.6^{\circ}\end{array}$ & $\begin{array}{l}81.1^{\circ} \% \\
76.0^{\circ}\end{array}$ & $\begin{array}{l}82.3^{\circ} \% \\
75.3^{\circ}\end{array}$ \\
\hline Max Temperature & $\begin{array}{l}95.9^{\circ} \\
84.0^{\circ}\end{array}$ & $\begin{array}{l}93.4^{\circ} \% \\
83.3^{\circ}\end{array}$ & $\begin{array}{l}103.1^{\circ} \% \\
85.3^{\circ}\end{array}$ & $\begin{array}{l}101.3^{\circ} \% \\
84.7^{\circ}\end{array}$ & $\begin{array}{l}99.5^{\circ} / \\
84.0^{\circ}\end{array}$ \\
\hline Minimum Temperature & $\begin{array}{l}61.0^{\circ} \% \\
61.2^{\circ}\end{array}$ & $\begin{array}{l}67.3^{\circ} \% \\
68.5^{\circ}\end{array}$ & $\begin{array}{l}66.2^{\circ} / \\
60.4^{\circ}\end{array}$ & $\begin{array}{l}63.7^{\circ} \% \\
57.6^{\circ}\end{array}$ & $\begin{array}{l}69.8^{\circ} \\
61.0^{\circ}\end{array}$ \\
\hline Humidity & 59.5 & 63.1 & 54.0 & 65.8 & 65.3 \\
\hline
\end{tabular}

Personal Monitoring of Occupational Heat Exposure Study, 2016

Figure 3. Individual results packet, page 1: summary tables of individual and site-specific maximum, minimum, and average measured temperature. able in English and Spanish languages. The report-back survey contained a variety of question formats, including demographic questions, Likert Scale response statements (Likert, 1932), multiple choice questions, and open-ended short answer questions. The

\section{A Guide to Understanding How Your Personal Temperature Measurements Compare to the Local Weather Station Use these plots to: \\ - Better understand how the temperatures you experienced at work over the 5-day study period compared with temperatures reported at the local weather station closest to campus for that same period. \\ - Evaluate how the daily weather forecast might be higher or lower than the temperatures that you will experience while at work and plan your work activities accordingly. Example summary results \\ - On average, all of your personal temperature exposure measures were higher than temperatures reported at your local weather station. \\ - Your personal temperature results are in teal and the weather station results are in red.}

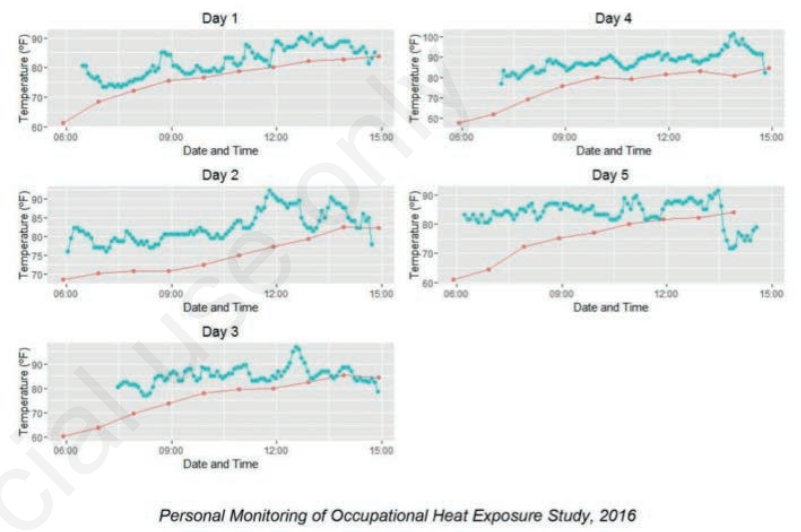

Figure 4. Individual Results Packet, Page 4: daily plots showing individual temperature and weather station temperature.

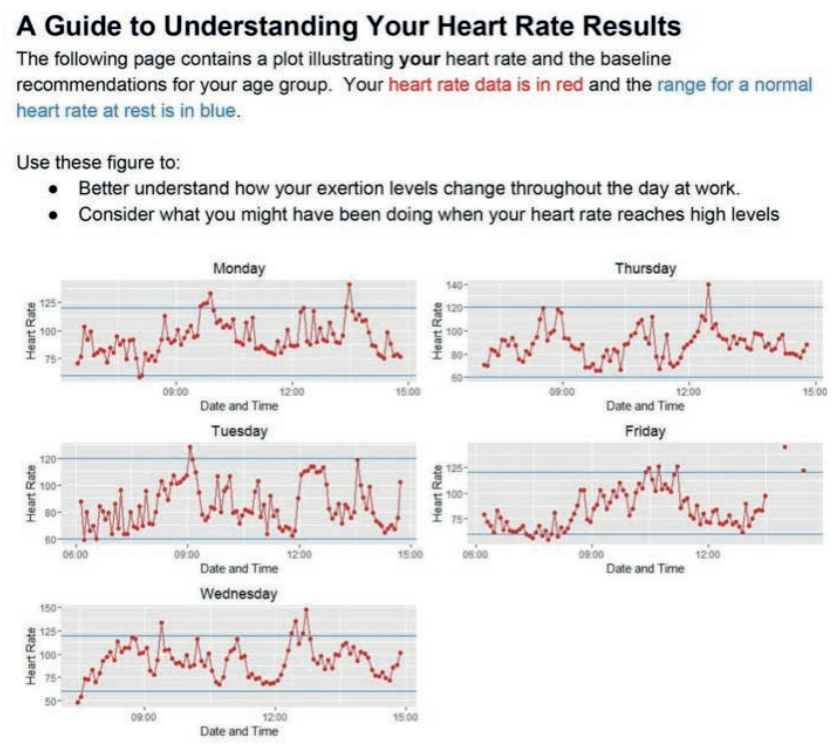

Personal Monitoring of Occupational Heat Exposure Study, 2016

Figure 5. Individual results packet, page 5: daily plots showing individual heart rate and recommended range based on age. 
following four questions were used to guide survey development: i) What are the participant's response and feelings in regards to their report-back information?; ii) What are the factors that drive response variation among participants across worksites?; iii) Does raising awareness of heat-related illness through individual sensor data collection affect attitude or behavioural change at the level of the individual or worksite?; iv) What is the potential for future occupational health studies in this population, particularly research involving the use of smartphone technology?

\section{Statistical analysis}

Survey answers were numerically coded and all descriptive analysis was conducted in SAS software (version 9.4; SAS Institute Inc., Cary, NC, USA) using the non-parametric Mann-Whitney U tests for Likert scale variables and the Kruskal-Wallis Test for the inclusion of three groups, as well as Chi-Square tests and Fisher's exact tests to compare categorical responses (counts and percentages) between groups. All tests were two-tailed and significance was evaluated at alpha $=0.05$. Report-back survey results were analyzed for each individual study site and for all sites combined.

\section{Participant $\mathrm{X}$}
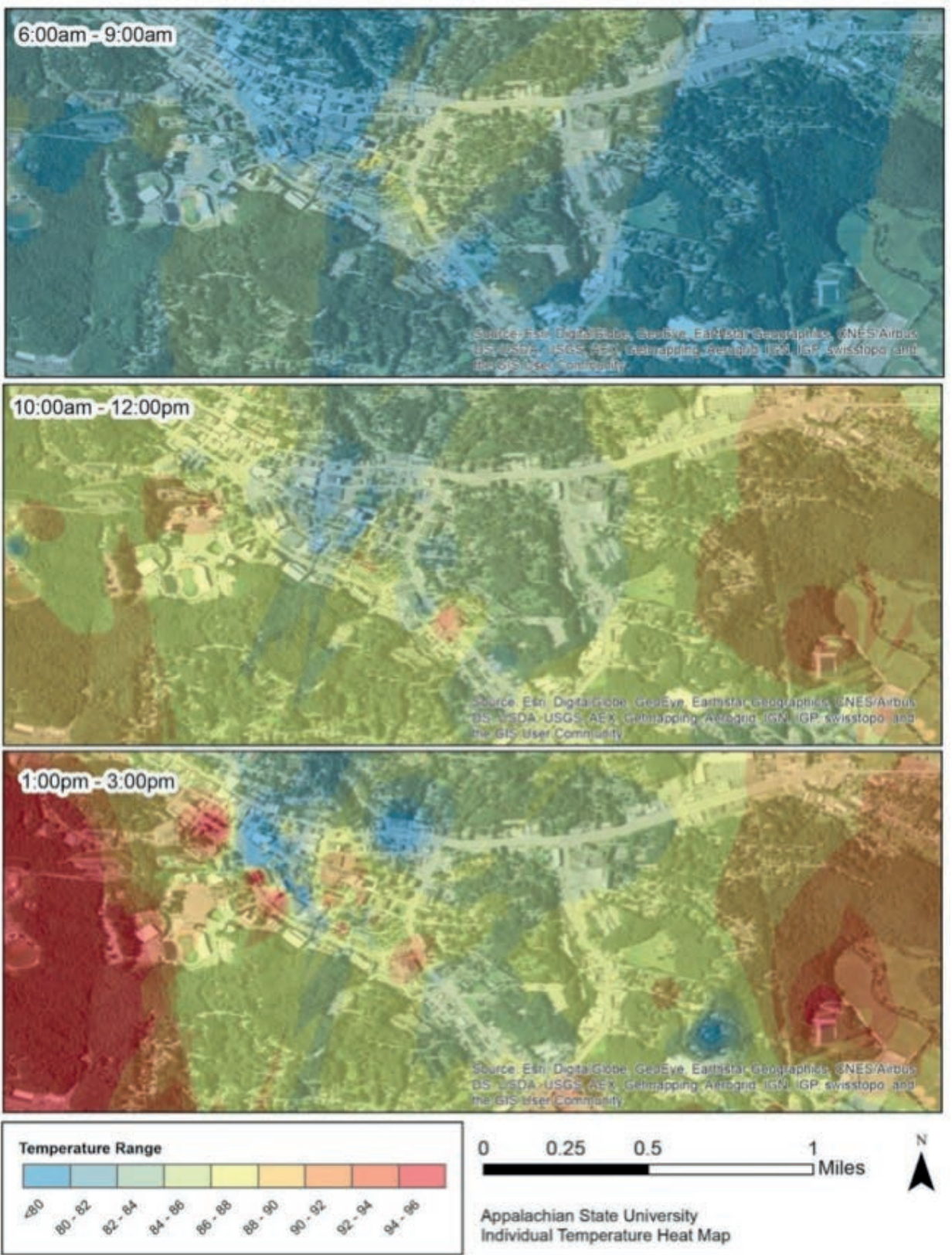

Appalachian State University Individual Temperature Heat Map

Personal Monitoring of Occupational Heat Exposure Study, 2016

Figure 6. Individual results packet, page 8: individual interpolated temperature exposure throughout campus. 


\section{Results}

Table 1 shows survey participation resulting in a total response rate of $94 \%$ and provides an overview of demographic characteristics for this sample of outdoor workers across the three study locations. Workers at ASU and NCSU were predominantly white $(96 \%$ and $73 \%$, respectively), while a large proportion of MSU workers were black or African American (73\%). The NCSU group was characterized by $21 \%$ of Hispanic workers and only $76 \%$ of workers at this site spoke English as their primary language. A larger proportion of workers in the MSU (27\%) and NCSU (25\%) groups had a bachelor's degree compared to $16 \%$ of ASU workers. Roughly $80 \%$ of participants across all campus sites reported spending most of their workday outdoors (i.e. 7 to 8 hours). The overall response to report-back was highly positive among workers in all three groups. Nearly $90 \%$ of participants reported being interested in receiving their results, whereas an estimated $85 \%$ of all workers felt that their report-back data would improve health and decrease the risk of workplace injury. Participants most often listed a personal interest in health as their reason for participation in the study (77\%), but workers were also motivated to participate in research to help others $(72 \%)$ and to provide benefit to the larger outdoor worker community (62\%). The survey assessed a participant's emotional response (i.e. surprise, anger, fear, concern or no emotional response) to their monitoring results (Table 2). No differences in emotional response was observed between the location sites. A total of $73 \%(n=41$ responses) participants reporting hav- ing no emotional response, followed by $59 \%$ ( $n=27$ responses) of workers expressing surprise by their results. A large proportion of workers reported that they disagreed with experiencing anger $(71 \%)$, fear $(66 \%)$ or concern $(58 \%)$ upon receiving their individual results.

Figure 7 demonstrates what participants found useful about their study results. Nearly all outdoor workers were in agreement that their results were personally useful ( $\mathrm{n}=52$ responses, 96\%), helped educate about their workplace health risks ( $\mathrm{n}=53$ responses, $95 \%$ ), improved their understanding of heat as a health hazard $(n=54,94 \%)$ and were generally useful to the larger outdoor worker community ( $\mathrm{n}=52$ responses, $95 \%$ ). The greatest number of neutral responses were in relation to whether or not workers perceived that the report-back of their results was useful for relieving concerns about heat as a workplace hazard $(n=19$ responses, $37 \%$ ) or whether or not results were useful for motivating a change in personal behaviour ( $\mathrm{n}=18$ responses, $35 \%)$.

\section{Analysis of behavioural change}

Central to the purpose of report-back and enhanced EHL is the application of results by participants to make a behavioural change at work (e.g., spend more time in the shade or take more breaks). Before the study, the research team collected survey data on a sample of 76 workers from each of the three worksites attending a data recruitment session on perceptions and willingness to use wearable sensors to track heat exposure and GPS locations while at work. At baseline, $26 \%$ of the workers reported being very likely to change

Table 1. Demographic characteristics of outdoor grounds worker participants at three American academic campuses.

\begin{tabular}{|c|c|c|c|c|}
\hline & $\begin{array}{c}\text { Appalachian State } \\
\text { University }^{\mathrm{a}} \\
(\mathrm{n}=26)\end{array}$ & $\begin{array}{l}\text { Mississippi State } \\
\text { University }^{\mathrm{b}} \\
(\mathrm{n}=11)\end{array}$ & $\begin{array}{l}\text { North Carolina } \\
\text { State University } \\
\quad(n=29)\end{array}$ & $\begin{array}{c}\text { Total } \\
(\mathrm{n}=66)\end{array}$ \\
\hline Report-back surveys completed & $24(92 \%)$ & $8(73 \%)$ & $28(97 \%)$ & 60 \\
\hline Mean age, years (SD) & $38(11.9)$ & $37(13.0)$ & $42(12.7)$ & - \\
\hline Males & $25(96 \%)$ & $11(100 \%)$ & $29(100 \%)$ & 65 \\
\hline $\begin{array}{l}\text { Education } \\
\text { Some high school } \\
\text { High school } \\
\text { diploma/GED } \\
\text { Associate's Degree } \\
\text { Bachelor's Degree } \\
\text { Graduate/professional degree } \\
\text { Refused to answer }\end{array}$ & $\begin{array}{c}1(4 \%) \\
11(42 \%) \\
8(31 \%) \\
4(15 \%) \\
2(7 \%)\end{array}$ & $\begin{array}{c}0 \\
8(73 \%) \\
0 \\
3(27 \%) \\
0\end{array}$ & $\begin{array}{c}3(11 \%) \\
12(43 \%) \\
3(11 \%) \\
7(25 \%) \\
0 \\
3(11 \%)\end{array}$ & $\begin{array}{c}4 \\
31 \\
11 \\
14 \\
2 \\
3\end{array}$ \\
\hline $\begin{array}{l}\text { Race }{ }^{* * *} \\
\text { Black or African } \\
\text { American } \\
\text { White or Caucasian } \\
\text { American Indian/Alaska Native }\end{array}$ & $\begin{array}{c}0 \\
25(96 \%) \\
1(4 \%) \\
0\end{array}$ & $\begin{array}{c}8(73 \%) \\
3(27 \%) \\
0 \\
0\end{array}$ & $\begin{array}{c}1(3 \%) \\
21(73 \%) \\
0 \\
7(24 \%)\end{array}$ & $\begin{array}{c}9 \\
49 \\
1 \\
7\end{array}$ \\
\hline Hispanic* & 0 & 0 & $6(21 \%)$ & 6 \\
\hline English as primary language & $25(96 \%)$ & $11(100 \%)$ & $22(76 \%)$ & 58 \\
\hline $\begin{array}{l}\text { Relationship status** } \\
\text { Married } \\
\text { Never married } \\
\text { Divorced } \\
\text { Separated } \\
\text { Member of unmarried couple }\end{array}$ & $\begin{array}{c}19(76 \%) \\
5(19 \%) \\
1(4 \%) \\
0 \\
1(4 \%)\end{array}$ & $\begin{array}{c}4(36 \%) \\
7(64 \%) \\
0 \\
0 \\
0\end{array}$ & $\begin{array}{l}19(66 \%) \\
5(17 \%) \\
2(7 \%) \\
0 \\
3(10 \%)\end{array}$ & $\begin{array}{c}42 \\
17 \\
1 \\
0 \\
4\end{array}$ \\
\hline Medical condition $^{\circ}$ & $1(4 \%)$ & $1(10 \%)$ & $3(10 \%)$ & 5 \\
\hline
\end{tabular}

arural Boone, NC; ${ }^{b}$ urban Starkville, MS; ${ }^{c}$ urban Raleigh, NC; ${ }^{*}$-value $<.01 ; * *$ P-value $<.05 ; * * *$-value $<.0001 ;{ }^{\circ}$ Medical condition that currently limits the amount of time outdoors or working in hot environments. 
their work behaviour to reduce heat exposure compared to $46 \%$ of those who participated in the monitoring study (Figure 8). Some participants provided open-ended responses that indicated a likelihood to change their personal behaviour as well. For example, one worker responded it [individual report-back] gives me a better idea of how to take care of myself in the field and [I] will study in detail and follow suggestions.

Although not statistically significant, a larger percentage $(87 \%, n=13)$ of older participants ( $>50$ years of age) and workers aged $36-49$ years $(77 \%, n=12)$ were more likely to make changes in response to their exposure results compared to $56 \%$ of workers ages $25-35(n=19)$ and $40 \%$ of workers $18-24$ years of age $(n=5)$ who reported being neutral to a change in behaviour (Fisher exact test, $\mathrm{P}=0.15$ ) (Figure 9). Figure 10 demonstrates that the majority of participants with $10+$ years of experience $(88 \%, n=25)$ reported being more likely to make changes compared to only $23 \%$ of workers with less than 5 years of work experience $(n=13)$ and $33 \%$ of workers with 6-10 years of experience $(n=9)$ who reported being neutral to making a change (Fisher exact test, $\mathrm{P} \leq 0.01$ ).

What was useful about the personal report-back of your study results?

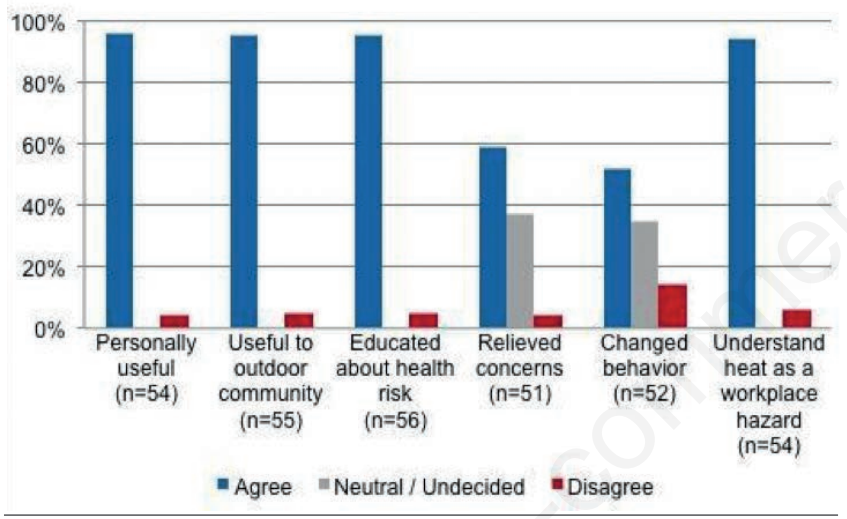

Figure 7. Worker response to the usefulness of individual reportback of study results for all study sites combined.

Are you more likely to change your behavior at work to reduce your exposure to heat?

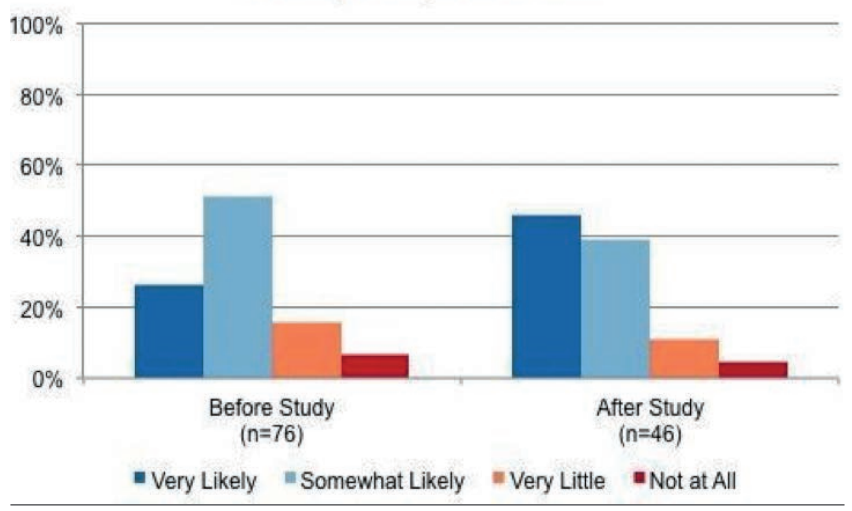

Figure 8. A comparison of results from surveys conducted before the study and following report-back sessions gauging likelihood of a work-related behavior change for all study sites combined.

\section{Report-back format: worker preference}

In general, workers agreed that each of the presentation formats of individual-level data (i.e. heat maps, box plots, summary tables, heart rate graph and heat recommendations) in the reportback were helpful in understanding their results (Table 2). However, the largest proportion of workers $(n=50,96 \%)$ agreed that the summary tables presenting a worker's daily individual experienced temperatures for that work-week in comparison to aggregate temperature experience for workers at the other two study locations was the most helpful followed by a strong preference for the heart rate graph $(n=46,94 \%)$ and heat recommendations $(\mathrm{n}=47,94 \%)$.

\section{Willingness to participate in future studies}

The majority of workers $(93 \%, n=44)$ reported that they were likely or somewhat likely to participate in sensor studies in the future and $74 \%(n=57)$ were likely to use a smartphone application to monitor temperature exposure at the workplace. There was no

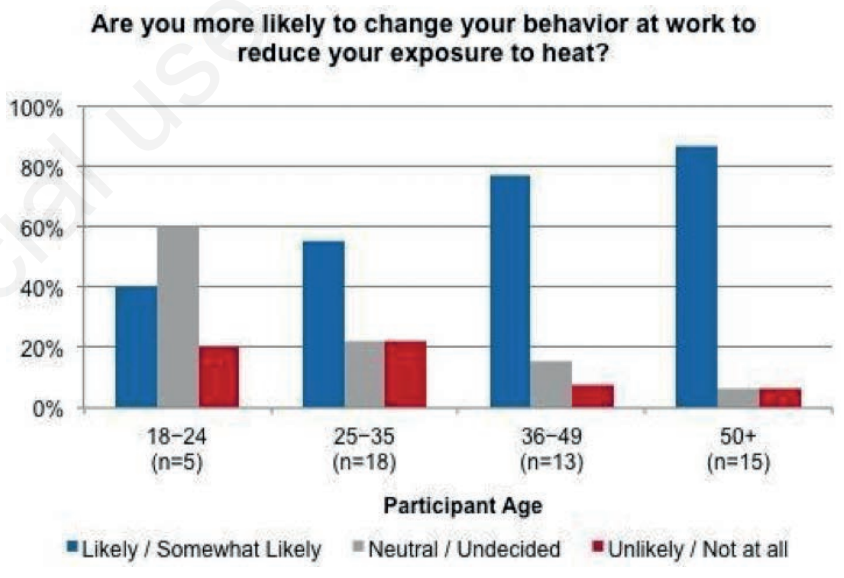

Figure 9. Worker response to the likelihood of a work-related behavior change by age group for all study sites combined.

Are you more likely to change your behavior at work to reduce your exposure to heat?

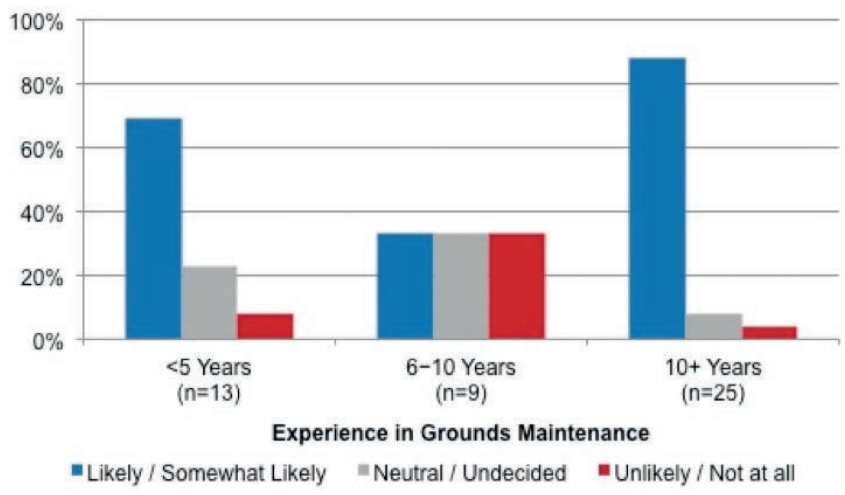

Figure 10. Worker response to the likelihood of a work-related behavior change by categories of work experience for all study sites combined. 
significant difference detected between age groups (i.e., $<36$ years $v s \geq 36$ years) and willingness to use a smartphone (Fisher exact test, $\mathrm{P}=.82$ ). Participants were most interested in future studies monitoring blood pressure $(n=42)$, air quality $(n=33)$, heart rate $(n=31)$ and wind chill $(n=30)$. Participants at NCSU were more interested in air quality monitoring (52\%), while ASU workers expressed greater interests in measuring the wind chill (53\%).

\section{Discussion}

The report-back of environmental monitoring results has the potential to become a powerful tool for individuals and communities to understand and respond to their personal exposures. Individual-level report-back provides participants with personal health information, and our findings suggest that report-back is a valued part of the study for many participants. In regards to personal health, one participant said, this info was great for possible health concerns, it tells me what I should work on. Overall, participants responded positively to their involvement in the study, were interested in receiving their results and expressed interest in participating in future environmental monitoring studies.

In terms of emotional response to individual results, results for these workers were similar to participants in previous report-back assessments. For example, surprise was a common response (reported by $45 \%$ of participants), while the minimal reporting of anger, fear or concern corroborated the low response of extreme negative emotions reported in similar report-back studies (Adams et al., 2011, Brody et al., 2014; Judge et al., 2016). Our findings suggest that report-back did not result in excessive worry or fear among participants and support its continued use for this population, as well as for other environmental monitoring studies. One participant mentioned a feeling of appreciation as a positive outcome of this study and included an open-ended response stating, Sometimes I think grounds workers are overlooked or looked down to because we do not make a lot of money, however it is great to know someone cares about the little people. This speaks more broadly to the ability of participatory environmental monitoring to engage underrepresented groups in environmental health science and promote feelings of value as study participants and members of the larger community.

Because participants could select multiple format preferences, there was a highly positive response among workers for each of the presentation formats used in the report-back. While this finding does not provide feedback on the most helpful presentation format, it does support the value in using multiple formats for presenting information to aid workers better understand their temperature exposure levels. Our results align with and support the recommendation from the Silent Spring Institute report-back handbook, which also recommends that the report-back should include presentations in text and graph form to address various visual preferences among participants for interpreting results (Dunagan et al., 2013).

With regard to response differences in the likelihood of a worker to implement behavioural change, we observed that only years of experience was a significant factor. Furthermore, a higher proportion of older participants reported a greater likelihood toward behavioural modification. More research is needed to understand why this difference occurs, but older participants might express a greater willingness to change workplace behaviour due to a higher overall concern for their health. Research suggests that older adults, particularly those still engaged in the workforce, exert a greater willingness to actively engage in health promoting behaviour to maintain their health and adapt to a changing workplace (Ng and Feldman, 2013; Ng and Law, 2014). With regard to years of experience, which is correlated with age, participants who worked in the field longer may feel they have a greater degree of behavioural control (i.e. locus of control) over their personal actions and workplace conditions ( $\mathrm{Ng}$ et al., 2006). In the workplace, the need to show productivity and document performance standards may lead to either worker or workplace imposing limits on break times further affecting a worker's ability to mitigate temperature exposures. However, one study that compared report-back success between two demographically different populations found that report-back was useful for behavioural change and actionbased responses, both in a middle-class, predominantly white community, and a working-class community with a higher minority population (Adams et al., 2011). More research is needed to understand the role of age, years of experience, cultural norms, and the influence of locus of control on a worker's motivation toward behavioural modification in response to heat stress on the job.

Table 2. Participant reactions to their study results following a report-back session.

\begin{tabular}{|c|c|c|c|}
\hline & Agree & Neutral/Undecided & Disagree \\
\hline \multicolumn{4}{|c|}{ What was your reaction to learning about your results from this study?* } \\
\hline Surprise & $27(59)$ & $10(22)$ & $9(20)$ \\
\hline Fear & $4(9)$ & $11(25)$ & $29(66)$ \\
\hline Anger & $2(5)$ & $10(24)$ & $29(71)$ \\
\hline Concern & $4(11)$ & $11(31)$ & $21(58)$ \\
\hline None & $41(73)$ & $4(7)$ & $11(20)$ \\
\hline \multicolumn{4}{|c|}{ Which of the following formats did you find the most helpful in understanding your survey results?* } \\
\hline Heat maps & $39(87 \%)$ & $3(7 \%)$ & $3(7 \%)$ \\
\hline Box plots & $45(88 \%)$ & $5(10 \%)$ & $1(3 \%)$ \\
\hline Heart rate graph & $46(94 \%)$ & $2(4 \%)$ & $1(2 \%)$ \\
\hline Heat recommendations & $47(94 \%)$ & $2(4 \%)$ & $1(2 \%)$ \\
\hline Summary tables & $50(96 \%)$ & $2(4 \%)$ & - \\
\hline
\end{tabular}

*No group level differences were observed across response categories. 


\section{Strengths and limitations}

While previous studies have used interviews to evaluate report-back, this study indicates the potential for using surveys in cases where conducting interviews may prove challenging or result in much lower participation. Surveys were chosen for this study to allow for minimal disruption of the worker's schedule and increase the response rate for report-back evaluation. While surveys are desirable for use in an occupational setting, we observed a low response rate for open-ended questions that could provide greater detail on the more subtle differences in perceptions of workers, particularly among rural participants. Future studies using survey evaluations can build upon this study and continue to develop new evaluation formats for gathering more descriptive data.

\section{Conclusions}

Our findings conclude that the report-back can be a powerful tool for improving Environmental Health Literacy in outdoor worker populations with increased exposure risks to heat stress. Many worker participants in this study expressed interests in participating in future studies expressing willingness to use a smartphone to monitor their temperature exposure at the workplace. Future studies involving the use of a smartphone application to track and report temperature-related exposure symptoms and monitor worker behaviour could be used to develop targeted alert notifications as workers reach harmful levels of exposure, allowing for real-time situational awareness. Age and years of experience most significantly affected an individual's likelihood to make a behavioural change to reduce temperature exposure, and future work should further examine the reasons for this response variation.

\section{References}

Adams C, Brown P, Morello-Frosch R, Brody JG, Rudel R, Zota A, Dunagan S, Tovar J, Patton S, 2011. Disentangling the exposure experience: the roles of community context and report-back of environmental exposure data. J Health Soc Behav 52:180-96.

Arguez A, Durre I, Applequist S, Vose RS, Squires MF, Yin X, Heim RRJr, Owen TW, 2012. NOAA's 1981-2010 U.S. Climate Normals: an overview. Bull Am Meteorol Soc 93:1687-97.

Bonney R, Phillips TB, Ballard HL, Enck JW, 2016. Can citizen science enhance public understanding of science? Publ Understand Sci 25:2-16.

Brody JG, Dunagan SC, Morello-Frosch R, Brown P, Patton S, Rudel RA, 2014. Reporting individual results for biomonitoring and environmental exposures: lessons learned from environmental communication case studies. Environ Health: Global Acc Sci Source 13:40.

Den Broeder L, Devilee J, Van Oers H, Schuit, AJ, Wagemakers A, 2016. Citizen Science for public health. Health Promot Int, daw086.

Dunagan SC, Brody J, Morello-Frosch R, Brown P, Goho S, Tovar J, Patton S, Danford R, 2013. When pollution is personal: handbook for reporting results to participants in biomonitoring and personal exposure studies. Newton, MA: Silent Spring
Institute.

Finn S, O'Fallon L, 2015. The emergence of environmental health literacy-from its roots to its future potential. Environ Health Perspect. Available from: http://dx.doi.org/10.1289/ ehp. 1409337

Goodchild MF, 2007. Citizens as sensors: the world of volunteered geography. Geo J 69:211.21.

Gould M, 2010. GIScience Grand challenges: how can research and technology in this field address big-picture problems? Arc User 13:64-5.

Kullenberg C, Kasperowski D, 2016. What is citizen science? A scientometric meta-analysis. PloS one 11:e0147152.

Judge JM, Brown P, Brody JG, Ryan S, 2016. The exposure experience: Ohio river valley residents respond to local Perfluorooctanoic Acid (PFOA) contamination. J Health Soc Behavior 57:333-50.

Likert R, 1932. A technique for the measurement of attitudes. Arch Psychol 140:1-55.

$\mathrm{Ng}$ ES, Law A, 2014. Keeping up! Older workers' adaptation in the workplace after age 55. Canad J Aging/Rev Canad Vieillissement 33:1-14.

$\mathrm{Ng}$ TW, Feldman DC, 2013. Employee age and health. J Vocat Behavior 83:336-45.

Ng TW, Sorensen KL, Eby LT, 2006. Locus of control at work: a meta $\square$ analysis. J Organiz Behavior 27:1057-87.

National Research Council-Mapping Science Committee, 2006. Beyond mapping: meeting national needs through enhanced geographic information science. Nat Acad Press.

Newman G, Wiggins A, Crall A, Graham E, Newman S, Crowston $\mathrm{K}, 2012$. The future of citizen science: emerging technologies and shifting paradigms. Frontiers Ecol Environ 10:298-304.

NIEHS, 2017. Environmental health literacy: the evolution of a new field. Available from: https://www.niehs.nih.gov/research/ supported/translational/peph/webinars/health_literacy/ Accessed: January 2017.

Ramirez-Andreotta M, Brody J, Lothrop N, Loh M, Beamer P, Brown P, 2016a. Improving environmental health literacy and justice through environmental exposure results communication. Int J Environ Res Pub Health 13:690.

Reis S, Seto E, Northcross A, Quinn NWT, Convertino M, Jones RL, Wimberly MC, 2015. Integrating modelling and smart sensors for environmental and human health. Environ Model Software 74:238-46.

Society for Public Health Education, 2016. What is environmental health literacy? Available from: http://www.sophe.org/ environmentalHealth/key_ehl.cfm. Accessed: August 2016.

Stepenuck KF, Green LT, 2015. Individual-and community-level impacts of volunteer environmental monitoring: a synthesis of peer-reviewed literature. Ecol Soc 20:19.

U.S. Census Bureau, 2015. 2015 population estimate: Raleigh, North Carolina. Available from: http://www.census.gov/quickfacts/table/PST045215/3755000. Accessed: December 2016.

U.S. Census Bureau, 2015. 2015 population estimate: Boone, North Carolina. Available from: http://www.census.gov/quickfacts/table/RHI105210/3707080. Accessed: December 2016.

U.S. Census Bureau, 2015. 2015 population estimate: Starkville, Mississippi. Available from: http://www.census.gov/quickfacts/table/PST045215/2870240. Accessed: December 2016. 